\title{
Sleep duration and weight loss among overweight/obese women enrolled in a behavioral weight loss program
}

\author{
EM O'Brien ${ }^{1}, \mathrm{~J} \mathrm{Fava}^{1}$, LL Subak ${ }^{2,3}, \mathrm{~K} \mathrm{Stone}^{4}, \mathrm{CN} \mathrm{Hart}^{1}, \mathrm{~K} \mathrm{Demos}^{1}$ and R Wing ${ }^{1}$
}

\begin{abstract}
OBJECTIVE: The purpose of this study was to examine whether baseline sleep duration predicts weight loss outcomes in a randomized controlled trial examining a behavioral weight loss (BWL) intervention among overweight and obese (OW/OB) women with urinary incontinence; and whether participation in the BWL intervention is associated with changes in sleep duration. DESIGN: Longitudinal, clinical intervention study of a 6-month BWL program.

SUBJECTS: Three hundred sixteen OW/OB women, with urinary incontinence (age: 30-81 years, body mass index (BMl; 25-50 $\mathrm{kg} \mathrm{m}^{-2}$ ) enrolled from July 2004-April 2006.

MEASUREMENTS: Measured height and weight, self-report measures of demographics, sleep and physical activity.

RESULTS: Neither self-reported total sleep time (TST) nor time in bed (TIB) at baseline significantly predicted weight loss outcomes among OW/OB women in a BWL treatment. BWL treatment was successful regardless of how much subjects reported sleeping at baseline, with an average weight loss of $8.19 \mathrm{~kg}$ for OW/OB women receiving BWL treatment, versus a weight loss of $1.44 \mathrm{~kg}$ in the control condition. Similarly, changes in weight, BMI and incontinence episodes did not significantly predict changes in sleep duration or TIB across the treatment period.

CONCLUSION: Although epidemiological and cross-sectional studies support a relationship between short sleep and increased BMI, the present study found no significant relationship between TST or TIB and weight loss for OW/OB women participating in a BWL treatment.
\end{abstract}

Nutrition and Diabetes (2012) 2, e43; doi:10.1038/nutd.2012.17; published online 10 September 2012

Keywords: sleep; behavioral treatment; weight loss; incontinence

\section{INTRODUCTION}

Over the past several decades, there has been a precipitous rise in the rates of obesity among adults, ${ }^{1}$ as well as a concomitant decrease of $1-2 \mathrm{~h}$ per night in the average reported sleep duration. $^{2}$ Epidemiological and cross-sectional studies have reported an association between short sleep duration and higher body mass index (BMI). ${ }^{3-7}$ Prospective studies examining the relationship between sleep duration and weight are limited, with mixed results emerging from these studies. ${ }^{8-11}$

There are few studies examining the relationship between sleep duration and outcomes from weight loss interventions. One recent study reported that baseline sleep duration significantly predicted success in a behavioral weight loss (BWL) program (defined as a weight loss of $\geqslant 10 \%$ ) but did not predict amount of actual weight loss. $^{12}$ In contrast, in the Finnish Diabetes Prevention Study baseline sleep duration did not predict weight changes over 3 years. $^{13}$

The Finnish DPP study, ${ }^{13}$ is the only study we are aware of that examined the effect of participation in a BWL program on sleep duration. Participants in the BWL group who reported sleeping $6.5 \mathrm{~h}$ or less at baseline had a significant increase their selfreported sleep by $0.9 \mathrm{~h}$ at the 1-year follow-up compared with the group sleeping $7-8.5 \mathrm{~h}$ per night at baseline. Conversely, in the control group, at the 1-year follow-up those who reported sleeping $6.5 \mathrm{~h}$ or less at baseline had a significant decrease in their self-reported sleep by $1.2 \mathrm{~h}$, and those who reported sleeping $10 \mathrm{~h}$ or more at baseline had a significant increase in their selfreported sleep by $0.7 \mathrm{~h}$ compared with the group sleeping $7-8.5 \mathrm{~h}$ per night at baseline.

The purpose of this study is to extend these observations by examining: (1) whether baseline sleep duration predicts weight loss outcomes in a randomized controlled trial examining a BWL intervention among overweight and obese (OW/OB) women with urinary incontinence; and (2) whether there are changes in sleep duration among participants in a BWL intervention. The present study also assesses these questions separately for Caucasian and African-American women, as there are well-established differences between self-reported sleep duration among Caucasian and African-American populations (for example, Lauderdale et al. ${ }^{14}$ ). Investigation of participants' baseline characteristics across time in bed (TIB) categories presented previously, ${ }^{15}$ indicated that shorter TIB was associated with higher BMI and lower physical activity compared with the referent category of '>7-8 $h$,' after adjusting for covariates. The present analyses focus on longitudinal associations between sleep and weight loss in this sample.

\section{SUBJECTS AND METHODS}

Participants

Data reported in this manuscript were collected as part of a multi-site randomized controlled trial testing a BWL intervention among OW/OB

${ }^{1}$ Department of Psychiatry and Human Behavior, Warren Alpert Medical School, Brown University, Providence, RI, USA; ${ }^{2}$ Departments of Obstetrics, Gynecology and Reproductive Sciences, Urology and Epidemiology and Biostatistics, University of California, San Francisco, CA, USA; ${ }^{3}$ UCSF Women's Health Clinical Research Center, San Francisco, CA, USA and ${ }^{4}$ California Pacific Medical Center Research Institute, San Francisco, CA, USA. Correspondence: Dr EM O'Brien, Weight Control and Diabetes Research Center, Warren Alpert Medical School, Brown University, 196 Richmond Street, Providence, RI 02903, USA.

E-mail: eobrien4@lifespan.org

Received 23 July 2012; accepted 24 July 2012 
women (BMI 25-50), age 30 or older, with urinary incontinence (PRIDE: Program to Reduce Incontinence by Diet and Exercise). The PRIDE study was conducted at Brown University in Providence, Rl, and the University of Alabama at Birmingham. The final sample included 338 OW/OB women, enrolled from July 2004-April 2006. For the present analysis, 22 women were excluded from the original sample of 338 for the following reasons: 11 for indicating that their race was neither African-American nor Caucasian; 9 for suspected shift work or circadian disturbances, and 2 due to having extreme outlying values on the Block Food Frequency questionnaire.

\section{Procedures}

Details about the study design have been presented previously in Subak et al. ${ }^{16}$ Procedures during months 1-6 will be described briefly here. Eligible participants were randomly assigned in a 2:1 ratio to an intensive BWL program or to a control condition. During months $1-6$, the BWL intervention had hour-long weekly meetings, where participants were provided with a calorie goal of 1200-1500 calories per day, a fat gram goal equal to $\leqslant 30 \%$ of calories from fat, and physical activity goals to gradually increase physical activity to $200 \mathrm{~min}$ per week. Additionally, sample meal plans and vouchers for meal replacement products were provided to increase adherence. Finally, behavioral skills were taught to help participants make changes to their eating habits and physical activity levels. The control group consisted of four $1 \mathrm{~h}$ group sessions (at months 1 , 2, 3 and 4), where structured information was provided about weight loss, physical activity and healthful eating habits. Sleep was measured, but not targeted, as part of the intervention. Participants in both groups completed a battery of measures at baseline and following the 6-month intervention period.

\section{Anthropometrics}

Height and weight were measured at baseline and 6 months. Participants were weighed in their clothes, without shoes, using a calibrated digital scale (Tanita BWB 800, Arlington Heights, IL, USA). Weight was measured to the nearest $0.5 \mathrm{~kg}$. Height was measured to the nearest centimeter using a calibrated, wall-mounted stadiometer. Measured height and weight were used to calculate BMI $\left(\mathrm{kg} \mathrm{m}^{-2}\right)$.

\section{Demographics and health behaviors}

Participants provided information about their age, race, education level and employment status, and completed the Beck Depression Inventory as a measure of depressive symptoms at baseline and 6 months.

\begin{abstract}
Sleep
Self-reported sleep information was obtained using the Pittsburgh Sleep Quality Index (PSQI; ${ }^{17}$ ), a widely-used and well-validated measure of general sleep habits and quality over the past month. Two items assessing usual bedtime and usual rise time over the past month were used to calculate participants' TIB, which was categorized as follows: $\leqslant 6 \mathrm{~h},>6$ to $\leqslant 7 \mathrm{~h},>7$ to $\leqslant 8 \mathrm{~h}$ (referent category), $>8$ to $\leqslant 9 \mathrm{~h}$ and $>9 \mathrm{~h}$. The category of $>7$ to $\leqslant 8 \mathrm{~h}$ was selected as the referent category because this amount of sleep has been associated with the lowest risk of obesity.,18 Total sleep time (TST) was assessed from the following item on the PSQI, 'During the past month, how many hours of actual sleep did you get at night? (This may be different than the number of hours you spent in bed).' Self-reported TST was categorized as follows: $<6 \mathrm{~h}, \geqslant 6$ to $<7 \mathrm{~h}, \geqslant 7$ to $<8 \mathrm{~h}$ (referent category), $\geqslant 8$ to $<9 \mathrm{~h}$ and $\geqslant 9 \mathrm{~h}$. Sleep onset latency was assessed by a question asking participants how long it took them to fall asleep. Sleep efficiency was calculated as the percent of time spent asleep within the total TIB period. Additionally, frequency of snoring or coughing loudly was obtained from the PSQI as a marker for sleep disordered breathing.
\end{abstract}

\section{Urinary incontinence}

Participants completed a 7-day voiding diary. These are valid and reliable measures of urinary incontinence episodes, ${ }^{19,20}$ and diaries were reviewed by trained research staff. Total weekly incontinence episodes were used in the present analyses.

\section{Statistical analysis}

All analyses were conducted using PASW Statistics 18, Release 18.0.0 (SPSS, Inc., 2009, Chicago, IL, USA; www.spss.com). Descriptive analyses were conducted for demographic and weight-related variables at baseline and at 6 months. The urinary incontinence variable was skewed, therefore logtransformed values for this variable were used in the analyses. Reported TIB was categorized to examine relationships in comparison with a referent category of ' $>7$ to $8 \mathrm{~h}$ ' of sleep per night. Similarly, self-reported TST was categorized to examine relationships in comparison with a referent category of ' $\geqslant 7$ to $<8 \mathrm{~h}$ ' of sleep per night. One-way analyses of variance and $\chi^{2}$ analyses were used to examine differences in demographic and clinical variables across TIB and TST categories. Variables that were found to vary across TIB and TST groups $(P<0.05)$, or were considered to be of conceptual importance as related to sleep or weight, were included in the analyses as covariates. These included the following baseline variables: age, race, education, baseline weight, group assignment, depression scores, PSQI total score and total incontinence episodes. Linear regression analyses were conducted to examine whether baseline TIB or baseline TST predicted changes in weight during the 6-month BWL intervention. For each regression analysis, TIB or TST was entered in the first step, followed by the covariates listed above. Linear regression analyses were also conducted to examine whether changes in weight or BMI from baseline to 6 months predicted changes in self-reported TST across the 6-month study period. For each regression analysis, change in weight or change in BMI was entered in the first step, followed by the covariates listed above. Analyses examining the relationship between sleep and weight were also conducted separately for Caucasian and African-American women to examine potential racial/ethnic differences in these relationships. Quadratic contrasts were also conducted using Stata/SE 12.0 for Windows (StataCorp., 2011, College Station, TX, USA; www.stata.com), in order to examine weight change across TST groups.

\section{RESULTS}

\section{Subject characteristics}

On average, participants were $53+/-11$ years, with a BMI of $36+/-6$, and had $24+/-18$ incontinence episodes per week. Approximately $78 \%$ of the sample was Caucasian and $19 \%$ of the sample was African-American. At baseline, participants in the BWL group slept for $6.60 \pm 1.24 \mathrm{~h}$, and participants in the control group slept for $6.44 \pm 1.19 \mathrm{~h}(P>0.05)$. Baseline sleep variables across the five TST categories are presented in Table 1.

\section{Sleep duration and weight loss}

Overall, participants in the BWL group had an average weight loss of $8.19 \pm 6.11 \mathrm{~kg}(8.41 \pm 6.10 \%)$ at 6 months, whereas the control participants had an average weight loss of $1.44 \pm 3.96 \mathrm{~kg}$ $(1.53 \pm 4.05 \% ; P<0.001)$. Figure 1 shows the average weight losses for participants in each of the five TST groups. Although the figure suggests somewhat better weight losses in those with the recommended $7-8 \mathrm{~h}$ of sleep per night, none of the differences in weight loss among the five TST groups were close to being statistically significant. Moreover, in linear regression analyses, neither TIB nor TST at baseline significantly predicted weight loss following BWL treatment, before or after accounting for age, race, education, baseline weight, depression, sleep quality and total incontinence episodes (Tables $2 a$ and b). Similarly, quadratic contrasts indicated that TST group did not predict weight loss in the BWL treatment. There was a small but significant correlation between reporting less difficulty falling asleep within $30 \mathrm{~min}$ at baseline and better subsequent weight loss $(r=0.17, P<0.05)$. However, sleep efficiency at baseline did not predict subsequent weight loss.

Notably, African-American participants reported significantly shorter TST than Caucasian participants (5.70 (1.12) hours vs 6.74 (1.17) hours, respectively; $P<0.001$ ). African-American participants also lost significantly less weight in the BWL group $(5.61 \mathrm{~kg}$ vs $8.83 \mathrm{~kg}$, respectively; $P<0.01)$ compared with Caucasian participants. However, linear regression analyses conducted separately for Caucasian women and African-American women indicated that 
Table 1. Sleep variables across the 5 TST groups

\begin{tabular}{|c|c|c|c|c|c|c|}
\hline & \multicolumn{6}{|c|}{ Sleep categories } \\
\hline \multicolumn{7}{|l|}{ Variables } \\
\hline $\begin{array}{l}\text { TIB (hours) } \\
\text { M (s.d.) }\end{array}$ & $\begin{array}{c}6.80 \\
(1.48)\end{array}$ & $\begin{array}{c}7.55 \\
(1.09)\end{array}$ & $\begin{array}{c}7.84 \\
(0.92)\end{array}$ & $\begin{array}{c}8.53 \\
(0.90)\end{array}$ & $\begin{array}{c}9.58 \\
(0.99)\end{array}$ & $27.56^{* * *}$ \\
\hline $\begin{array}{c}\text { SOL (min) } \\
\text { M (s.d.) }\end{array}$ & $\begin{array}{c}28.50 \\
(25.00)\end{array}$ & $\begin{array}{c}22.31 \\
(17.50)\end{array}$ & $\begin{array}{c}17.65 \\
(19.02)\end{array}$ & $\begin{array}{l}13.44 \\
(9.72)\end{array}$ & $\begin{array}{c}15.91 \\
(15.46)\end{array}$ & $5.98^{* * *}$ \\
\hline SE (\%) & $72.6 \%$ & $81.3 \%$ & $90.4 \%$ & $94.8 \%$ & $96.4 \%$ & $29.40^{* * *}$ \\
\hline
\end{tabular}

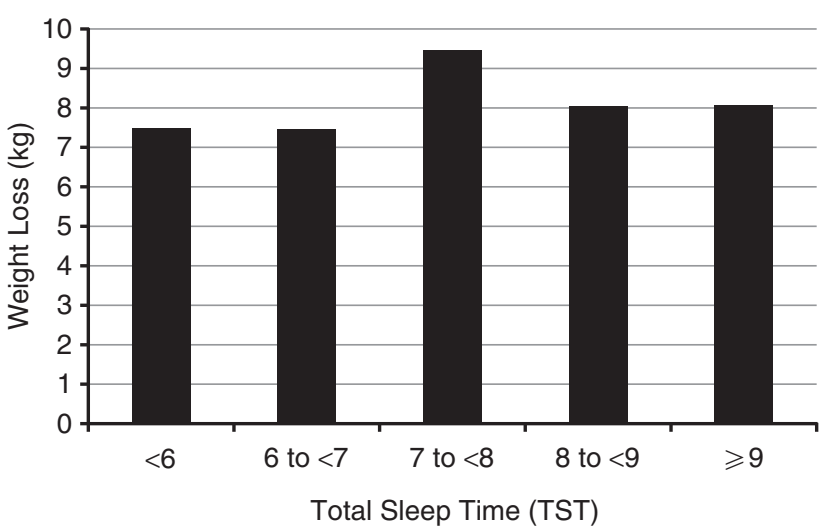

Figure 1. Weight loss $(\mathrm{kg})$ for Program to Reduce Incontinence by Diet and Exercise (PRIDE) participants receiving behavioral weight loss (BWL) treatment.

there were no significant relationships between TIB or TST and weight loss for either of the two racial/ethnic groups in the BWL or control group.

\section{Sleep following BWL treatment}

On average, participants reported little change in their TST from baseline to 6 months (BWL: $M=+0.08 \mathrm{~h}$; control: $M=+0.07 \mathrm{~h}$ ). Additionally, there were no significant time effects, group effects or interactions for changes in TST or sleep disruptions due to needing to use the bathroom. Linear regression analyses indicated that neither changes in weight, changes in BMI nor changes in urinary incontinence episodes from baseline to 6 months predicted changes in self-reported TST, before or after accounting for age, race, education, group assignment, depression, sleep quality and total incontinence episodes. Separate analyses for African-American and Caucasian women, and for only those participants in the treatment group, again showed no effect of changes in weight, BMI or urinary incontinence on changes in TST. Short and long sleepers in both the BWL and control groups reported a more moderate TST at 6 months compared with their baseline TST, indicating a regression toward the mean (Figure 2). Sensitivity analyses were also conducted among only those participants who indicated infrequent coughing or loud snoring during sleep (that is, less than once per week; used as a proxy to assess for likelihood of sleep apnea). There were no changes in the
Table 2. TST (a) and TIB (b) as predictors of weight change (\%) from baseline to 6 months following BWL treatment

\begin{tabular}{|c|c|c|c|c|}
\hline & $B$ & SE & Beta & $\mathrm{t}$ \\
\hline \multicolumn{5}{|l|}{ (a) TST } \\
\hline \multicolumn{5}{|l|}{ Variables } \\
\hline Total sleep time (TST) & 0.25 & 0.36 & 0.05 & 0.69 \\
\hline Ethnicity (AA/C) & -3.09 & 0.90 & -0.19 & $-3.45^{* *}$ \\
\hline Age & 0.02 & 0.03 & 0.02 & 0.45 \\
\hline Education & -1.24 & 0.66 & -0.10 & -1.87 \\
\hline Baseline weight & -0.02 & 0.02 & -0.06 & -1.09 \\
\hline $\begin{array}{l}\text { Total incontinence } \\
\text { episodes }^{\mathrm{a}}\end{array}$ & -0.50 & 0.49 & -0.05 & -1.02 \\
\hline $\begin{array}{l}\text { Beck depression } \\
\text { score }\end{array}$ & 0.14 & 0.07 & 0.12 & $2.05^{*}$ \\
\hline PSQI total score & 0.04 & 0.12 & 0.03 & 0.36 \\
\hline $\begin{array}{l}\text { Intervention group } \\
\text { (treatment/control) }\end{array}$ & 0.62 & 0.70 & 0.48 & $9.45^{* * *}$ \\
\hline \multicolumn{5}{|l|}{ (b) $T I B$} \\
\hline \multicolumn{5}{|l|}{ Variables } \\
\hline Time in bed (TIB) & 0.00 & 0.00 & 0.01 & 0.24 \\
\hline Ethnicity (AA/C) & -2.96 & 0.89 & -0.18 & $-3.34^{* *}$ \\
\hline Age & 0.01 & 0.03 & 0.02 & 0.44 \\
\hline Education & -1.18 & 0.66 & -0.09 & -1.80 \\
\hline Baseline weight & -0.02 & 0.02 & -0.06 & -1.12 \\
\hline $\begin{array}{l}\text { Total incontinence } \\
\text { episodes }^{\mathrm{a}}\end{array}$ & -0.51 & 0.49 & -0.05 & -1.04 \\
\hline $\begin{array}{l}\text { Beck depression } \\
\text { score }\end{array}$ & 0.14 & 0.07 & 0.13 & $2.12^{*}$ \\
\hline PSQI total score & -0.01 & 0.10 & -0.00 & -0.07 \\
\hline $\begin{array}{l}\text { Intervention group } \\
\text { (treatment/control) }\end{array}$ & 6.59 & 0.70 & 0.48 & $9.42^{* * *}$ \\
\hline
\end{tabular}

Abbreviation: PSQI, Pittsburgh Sleep Quality Index. ${ }^{*} P<0.05$; ${ }^{*} P<0.01$; ${ }_{* * *} P<0.001$. ${ }^{\mathrm{a}} \mathrm{This}$ variable was log-transformed due to being skewed.

preceding results when examined only among participants who were less likely to have sleep apnea.

\section{DISCUSSION}

The main finding of this study was that neither TIB nor TST at baseline predicted weight loss outcomes among OW/OB women in a BWL treatment. BWL treatment was successful regardless of how much subjects reported sleeping at baseline, with an average weight loss of $8.19 \mathrm{~kg}$ for women in the BWL group versus a weight loss of $1.44 \mathrm{~kg}$ in the control condition. Less sleep 


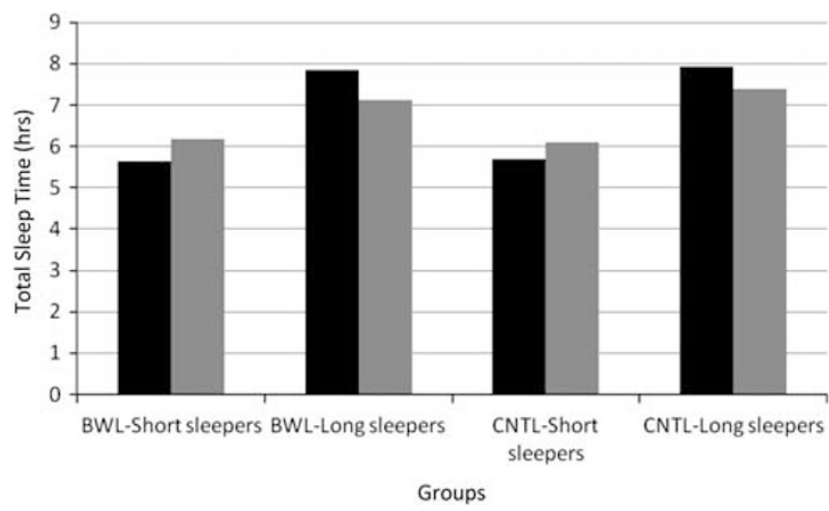

Figure 2. Changes in self-reported total sleep time (in hours) from baseline (black bars) to 6 months (gray bars) in the behavioral weight loss (BWL) and control groups.

fragmentation at baseline was significantly, but modestly, correlated with better subsequent weight loss outcomes, whereas baseline sleep efficiency was not related to weight loss.

The present study is one of the first to examine the relationship between TIB and TST and weight loss outcomes among OW/OB individuals participating in a weight loss intervention. In contrast to the findings of Elder et al., ${ }^{12}$ but replicating data from the Finnish DPP study, $^{13}$ the present findings suggest that selfreported TIB and self-reported TST do not significantly predict weight loss outcomes in a BWL treatment.

The other important finding was that the changes in weight, $\mathrm{BMI}$ and urinary incontinence that occurred over the 6-month weight loss program were not associated with changes in selfreported TST. Self-reported TST for both short and long sleepers in the BWL and control groups moved toward more moderate amounts across the 6-month treatment period, suggesting regression to the mean.

Similar to previous studies (for example, Vgontzas et $a l^{24}$ ), higher depression scores and poorer sleep quality were endorsed by participants reporting shorter TST. A considerable body of research has established an association between depression and impairments in sleep quality or quantity. ${ }^{25-27}$ However, elevated depression scores and impaired sleep quality were not found among long sleepers in the present sample. This may have been influenced by the small number of participants in the current sample, who reported sleeping 9 or more hours per night.

Results also showed that African-American women reported less sleep at baseline $(5.70 \mathrm{~h}$ overall vs $6.74 \mathrm{~h}$ overall; $P<0.001)$ compared with Caucasian women and lost significantly less weight $(5.61 \mathrm{~kg}$ vs $8.83 \mathrm{~kg} ; P<0.01)$ in the BWL group. This is consistent with existing literature reporting shorter self-reported and objectively measured sleep duration among African-American adults (for example, Lauderdale et al. ${ }^{14}$ ), as well as poorer weight loss outcomes (for example, Fitzgibbon et al. ${ }^{28}$ ) compared with Caucasian adults. However, there was no relationship between TST and weight loss within either racial/ethnic group. In other words, even though the African-American women in this study lost less weight and obtained less sleep, there was no association between these two factors among this group of participants. AfricanAmericans made up $\sim 19 \%$ of the sample, so it is possible that this small number of African-American participants affected our ability to detect ethnic differences in this study.

Although this study had several strengths, including use of a randomized controlled design and longitudinal assessment, results should also be interpreted in relation to limitations. The present sample included $O W / O B$ female participants with urinary incontinence. Incontinence is common among $\mathrm{OW} / \mathrm{OB}$ adults $^{29}$ and was controlled for in all analyses. TST was based on self-report, which is consistent with much of the existing epidemiological, cross-sectional and prospective literature. It is possible that use of an objective measure of sleep may have provided further insight into the relationships under study. In particular, given the relatively short period of study (that is, 6 months), it may be that individuals do not perceive changes in their sleep patterns, though subtle changes may be occurring. Use of objective measures of sleep would be beneficial to further investigate these relationships. Additionally, future studies should examine whether intervening to increase sleep duration or improve sleep quality has a beneficial impact on weight loss outcomes. A recent study by Chaput et al. ${ }^{30}$ reported that short sleepers (defined as $\leqslant 6 \mathrm{~h}$ per day) who increased their sleep duration to $7-8 \mathrm{~h}$ per day over a 6-year period had a smaller increase in BMI and fat mass, compared with short sleepers who maintained their short sleep durations over the same period. This suggests that increasing sleep duration to a healthy duration of 7-8h per day may be an important strategy for preventing weight gain. Additionally, little is known about the impact of maintaining weight loss on subsequent sleep habits. The present study examined the relationship between sleep and weight loss across a 6-month period. Future studies should examine whether maintaining a lower body weight following BWL treatment has a beneficial impact on sleep.

Though epidemiological and cross-sectional studies support a relationship between short sleep and increased $\mathrm{BMI}$, this relationship is poorly understood. Limited prospective data have examined this relationship, and reports from these studies have provided conflicting results. After controlling for multiple potential confounding variables, including incontinence, the present study found that reported TIB and TST do not predict weight loss for $\mathrm{OW} / \mathrm{OB}$ women participating in a BWL treatment. This highlights the complex relationship between sleep and weight and suggests that future studies need to examine this relationship more thoroughly using objective measures, longitudinal designs and interventions aimed at improving sleep.

\section{CONFLICT OF INTEREST}

The authors declare no conflict of interest.

\section{ACKNOWLEDGEMENTS}

This work was supported by NIDDK (U01 DK067860, U01 DK067861, U01 DK067862).

\section{REFERENCES}

1 Flegal KM, Carroll MD, Ogden CL, Curtin LR. Prevalence and trends in obesity among US adults, 1999-2008. Jama 2010; 303: 235-241.

2 National Sleep Foundation. Sleep in America. Gallup Organization: Princeton, NJ, 2008.

3 Kripke DF, Garfinkel L, Wingard DL, Klauber MR, Marler MR et al. Mortality associated with sleep duration and insomnia. Arch Gen Psychiatry 2002; 59 131-136.

4 Marshall NS, Glozier N, Grunstein RR. Is sleep duration related to obesity? A critical review of the epidemiological evidence. Sleep Med Rev 2008; 12: 289-298.

5 Patel SR, Hu FB. Short sleep duration and weight gain: a systematic review. Obesity 2008; 16: 643-653.

6 Taheri S, Lin L, Austin D, Young T, Mignot E. Short sleep duration is associated with reduced leptin, elevated ghrelin, and increased body mass index. PLOS Med 2004; 1: e62.

7 Van Cauter E, Knutson KL. Sleep and the epidemic of obesity in children and adults. Eur Soc Endocrinol. in press 2008; 159(Suppl 1): S59-S66.

8 Chaput JP, Després JP, Bouchard C, Tremblay A. The association between sleep duration and weight gain in adults: a 6-year prospective study from the Quebec Family Study. Sleep 2008; 31: 517-523.

9 Gangwisch JE, Malaspina D, Boden-Albala B, Heymsfield SB. Inadequate sleep as a risk factor for obesity: analyses of the NHANES I. Sleep 2005; 28: 1289-1296. 
10 Hasler G, Buysse DJ, Klaghofer R, Gamma A, Ajdacic V, Eich D et al. The association between short sleep duration and obesity in young adults: a 13-year prospective study. Sleep 2004; 27: 661-666.

11 Patel SR, Malhotra A, White DP, Gottlieb DJ, Hu FB. Association between reduced sleep and weight gain in women. Am J Epidemiol 2006; 164: 947-954.

12 Elder CR, Gullion CM, Funk KL, Debar LL, Lindberg NM, Stevens VJ et al. Impact of sleep, screen time, depression and stress on weight change in the intensive weight loss phase of the LIFE study. Int J Obes 2011; 36: 86-92.

13 Tuomilehto $\mathrm{H}$, Peltonen M, Partinen M, Lavigne G, Eriksson JG, Herder C et al. Sleep duration, lifestyle intervention, and incidence of type 2 diabetes in impaired glucose tolerance: The Finnish Diabetes Prevention Study. Diabetes Care 2009; 32: 1965-1971.

14 Lauderdale DS, Knutson KL, Yan LL, Rathouz PJ, Hulley SB, Sidney S et al. Objectively measured sleep characteristics among early-middle-aged adults: the CARDIA study. Am J Epidemiol 2006; 164: 5-16.

15 Hart CN, Fava JL, Subak LL, Stone KL, Cairns A, Demos KE et al. Shortened sleep duration is associated with increased bmi and decreased physical activity. Obesity 2011; 19(suppl 1): S98.

16 Subak LL, Wing R, West DS, Franklin F, Vittinghoff E, Creasman JM et al. Weight loss to treat urinary incontinence in overweight and obese women. $N$ Engl J Med 2009; 360: 481-490.

17 Buysse DJ, Reynolds 3rd CF , Monk TH, Berman SR, Kupfer DJ. The Pittsburgh Sleep Quality Index: a new instrument for psychiatric practice and research Psychiatry Res 1989; 28: 193-213.

18 Watanabe M, Kikuchi H, Tanaka K, Takahashi M. Association of short sleep duration with weight gain and obesity at 1-year follow-up: a large-scale prospective study. Sleep 2010; 33: 161-167.

19 Nygaard I, Holcomb R. Reproducibility of the seven-day voiding diary in women with stress urinary incontinence. Int Urogynecol J Pelvic Floor Dysfunct 2000; 11 15-17.

20 Wyman JF, Choi SC, Harkins SW, Wilson MS, Fantl JA. The urinary diary in evaluation of incontinent women: a test-retest analysis. Obstet Gynecol 1988; 71: 812-817.
21 Kohatsu ND, Tsai R, Young T, Vangilder R, Burmeister LF, Stromquist AM et al. Sleep duration and body mass index in a rural population. Arch Intern Med 2006; 166: 1701-1705.

22 Lauderdale DS, Knutson KL, Rathouz PJ, Yan LL, Hulley SB, Liu K. Cross-sectional and longitudinal associations between objectively measured sleep duration and body mass index: the CARDIA Sleep Study. Am J Epidemiol 2009; 170: 805-813.

23 Vorona RD, Winn MP, Babineau TW, Eng BP, Feldman HR, Ware JC. Overweight and obese patients in a primary care population report less sleep than patients with a normal body mass index. Arch Intern Med 2005; 165: 25-30.

24 Vgontzas AN, Lin HM, Papaliaga M, Calhoun S, Vela-Bueno A, Chrousos GP et al. Short sleep duration and obesity: the role of emotional stress and sleep disturbances. Int J Obes 2008; 32: 801-809.

25 Krueger PM, Friedman EM. Sleep duration in the United States: a cross-sectional population-based study. Am J Epidemiol 2009; 169: 1052-1063.

26 Perlis ML, Giles DE, Buysse DJ, Tu X, Kupfer DJ. Self-reported sleep disturbance as a prodromal symptom in recurrent depression. J Affect Disord 1997; 42: 209-212.

27 Riemann D, Voderholzer U. Primary insomnia: a risk factor to develop depression? J Affect Disord 2003; 76: 255-259.

28 Fitzgibbon ML, Tussing-Humphreys LM, Porter JS, Martin IK, Odoms-Young A, Sharp LK. Weight loss and African-American women: a systematic review of the behavioural weight loss intervention literature. Obes Rev 2012; 13: 193-213.

29 Subak LL, Richter HE, Hunskaar S. Obesity and urinary incontinence: epidemiology and clinical research update. J Urol 2009; $182(6$ Suppl): S2-S7.

30 Chaput JP, Després JP, Bouchard C, Tremblay A. Longer sleep duration associates with lower adiposity gain in adult short sleepers. Int J Obes 2012; 36: 752-756.

(c) This work is licensed under the Creative Commons AttributionWMERIGHS RESERVED NonCommercial-No Derivative Works 3.0 Unported License. To view a copy of this license, visit http://creativecommons.org/licenses/by-nc-nd/3.0/ 